\title{
Title: Early Persistence of Psychotic-Like Experiences in a community sample of adolescents
}

\section{Running title: Persistent Psychotic experiences in adolescents}

Authors: Danish Hafeez ${ }^{1 *}$; Alison R Yung ${ }^{2,3,4}$

1:School of Medical Sciences, The University of Manchester, Oxford Rd, Manchester M13 9PL, UK

2: Orygen, 35 Poplar Rd Parkville 3052, Vic, Australia

3: Centre for Youth Mental Health, The University of Melbourne

4: School of Health Sciences, The University of Manchester, Oxford Rd, Manchester M13 9PL, UK

Word Count:3462(including in-text citations)

Corresponding author: hafeez78@hotmail.co.uk

\section{Abstract (246 words)}

Aims: Psychotic-like experiences (PLEs) are common in adolescents. Their persistence may confer increased susceptibility to psychotic disorder. The early evolution of transient to persistent PLEs is not well known.This study aimed to investigate the early persistence of PLEs (over 6-12 months) in a community sample of adolescents and examinebaseline and longitudinal associations of early persistent PLEs.

Methods:Five hundred and ninety Year 10 students were administered the Community Assessment of Psychic Experiences (CAPE) to measure PLEs at baseline and at follow up 6-12 months later. Persistent PLEs were defined as those present at or above the $90^{\text {th }}$ centile at both time points. Independent variables of depression, psychological distress and functioning were all measured at both baseline and follow up. Self-esteem, personality and suicidality were assessed at follow up.

Results: The study found $5.1 \%$ of participants had early persistent PLEs. Persistence was associated positively with depression and distress at both time points, neuroticism and openness at baseline and suicidality at follow up. Persistence was negatively associated with functioning at both time points, agreeableness at baseline and self-esteem at follow-up. Only depression remained significantly associated at both time points when accounting for other variables. Thus, depressive symptoms may account for changes in other domains and be a predictor of early PLEs persistence.

ConclusionsThese results reinforce the importance of monitoringand assessing PLEs inyoung people especially when associated with depression. Further research is required to investigate PLE persistence over longer periods with increased measurement intervals.

\section{KEYWORDS: depression,persistence, psychosis, Psychotic-like experience, psychotic symptoms}

This is the author manuscript accepted for publication and has undergone full peer review but has not been through the copyediting, typesetting, pagination and proofreading process, which may lead to differences between this version and the Version of Record. Please cite this article as doi: 10.1111/eip.13096

This article is protected by copyright. All rights reserved. 


\section{INTRODUCTION}

Psychotic experiences occur on a continuum, between non-distressing experiences of low intensity, to those of high intensity and distress, as seen in psychotic disorders such as schizophrenia. Terminology is inconsistent in the literature. A recent review (Seiler, Nguyen, Yung \& O'Donoghue, 2020) recommends that the terms "psychotic-like experiences" or "psychotic experiences" are used for experiences that are low in intensity and distress. This contrasts with "attenuated psychotic symptoms" which are distressing although below the threshold for a diagnosis of psychotic disorder. These are characteristic of the "At Risk Mental State" (also known as the Ultra High Risk or Clinical High-Risk state)(Fusar-Poli et al., 2013). They include, for example, unusual thoughts that are not held with delusional conviction and abnormal perceptual experiences that are not true hallucinations, i.e. they do not have the quality of true perceptions.

The prevalence of psychotic-like experiences (PLEs) in general populations is high, from 17.5\% (lifetime prevalence) to 98\%(one PLE at least sometimes), depending on the criteria and group studied(Van Os, Hanssen, Bijl \& Vollebergh, 2001; Yung et al. 2005). A meta-analysis found the prevalence of PLEs to be 8\% (Van Os et al., 2008) which is even higher in children and adolescents (Nelson, Fusar-Poli \& Yung, 2012; Scott et al. 2009, Kelleher et al. 2012; Maijer, Begemann, Palmen, Leucht \& Sommer, 2017). PLEs during childhood and adolescence are associated with increased risk for developing both psychotic and non-psychotic disorders (Healy et al. 2019) although most PLEs do not develop into psychotic disorder. Rather, the majority of PLEs occurring during adolescence are likely to be transient (Zammit et al. 2013) and may not be associated with any clinical syndrome. However, adolescents have the greatest incidence of 
first episode psychosis (Simon et al. 2017), highlighting the need to identify those PLEs that are likely to develop into future psychopathology. Individuals with these PLEs may benefit most from early interventions.

The persistence of PLEs may indicate susceptibility for transition into mental health disorder. Previous studies (Dominguez, Wichers, Lieb, Wittchen, \& van Os, 2009; Bechtold, Hipwell, Lewis, Loeber, \& Pardini, 2016) found those with persistent PLEs had a greater risk of developing psychotic disorder than those with transient PLEs. However, a recent systematic review noted the need for more research examining the persistence of PLEs in this underexplored area (Healy et al. 2019). In particular, the early course of PLEs is unknown and so the transition from potentially benign transient PLEs to riskier persistent PLEs has not been well demarcated.

Kalman et. al. (2019)conducted a scoping review that showed although many studies have investigated multiple predictors of persistent PLEs, no predictors have been replicated across studies. One of the most widely investigated factors is depression which has tended to be higher in persistent groups although not always significantly. Personality traits, functioning, selfesteem, suicidalityand psychological distress (Shi et al., 2018; Haug et al., 2016; Nishida et al., 2010; Yamasaki et al., 2018)have been found to be associated with PLE prevalence.

Given these associations, and the paucity of literature in relation to risk factors for persistence of PLEs, we aimed to assess the relationship between depression, distress, suicidality, selfesteem and personality traits with PLEs. We studied (1) the early persistence of PLEs (over 612 months) in a community sample of adolescence. In addition, to further delineate the time course of early persistence we examined (2) baseline and longitudinal associations of early persistent PLEs. The longitudinal design provides an opportunity to investigate whether those factors associated with prevalence of PLEs can predict or are associated with their early persistence. 


\section{METHODS}

\section{Study design}

Aprospective longitudinal study of Year 10 students in Melbourne, Australia with follow up at 612 months after initial assessment.

\section{Subjects and Procedures}

Sixty secondary schools in Melbourne, Australia were asked to participate in the study and 34 agreed to their Year 10 students being surveyed. This was made up of 20 government, five Catholic and nine independent schools.

Questionnaires were used to assess participants from each school during a 48-minute study period.Trained research assistants were available to support students in class. These questionnaires wererepeated at follow-up on a second occasion approximately 6-12 months later in another 48-minute study period. All participants providedwritten informed consent from their parent/guardian and themselves. The study was approved by Research and Ethics Committees at the University of Melbourne, Victorian Department of Education and the Catholic Education Office.

\section{Measures}

PLEs were assessed using the Community Assessment of Psychic Experiences (CAPE) (Stefanis et al., 2002). This self-report measure is made up 42 items, with subscales of positive (20 items), negative (14 items) and depressive symptoms (8 items). The scale records both the frequency and distress associated with each item. In this study only the frequency measure (1=never, 4= nearly always) on the positive symptoms subscale was used (Total score: $20-80$ ). 
At baseline, participants were asked to assess the occurrence of PLEs in the preceding 12 months. At follow-up they were asked about PLEs since their last assessment. The CAPE has been validated in several adolescent samples (Mark \& Toulopoulou, 2015). There is no predetermined threshold for high PLEs

Depression was measured using the Center for Epidemiologic Studies Depression Scale (CESD). Twenty items are included in the CESD that rate frequency of depressive symptoms from 1 (rarely) to 4 (most of the time) (Radloff 1977).Scores $\geq 24$ have been linked to caseness of depression and the scale has beenvalidated for use in adolescents(Radloff, 1991).

Functioning was measured by the Multidimensional Adolescent Functioning Scale (MAFS). This scale is made up of 23 items scored on a $0-4$ scale ( $0=$ not at all, $4=$ always/almost always).A higher score indicates improved functioning. MAFS has been validated for adolescents (Wardenaar et al. 2013).

The General Health Questionnaire 12 (GHQ-12)was usedto assess psychological distress. It consists of 12 items including both depressive and anxiety symptom items. Each item is scored $0-3$ and total scores of $\geq 12$ have been associated with caseness of psychological distress (Goldberg et al. 1997). The GHQ-12 has been previously validated for adolescents (D'Arcy \& Siddique, 1984; Radovanović \& Erić, 1983).

Self-esteem was measured at follow up using the Rosenberg Self-Esteem inventory (RSE). This is 10 item scale where each item is rated 1-4 (1-strongly disagree, 4-strongly agree). An increase in cumulative score indicates higher self-esteem (Rosenberg, 1965).It has been validated in adolescents (Whiteside-Mansell \& Corwyn, 2003).

The Neuroticism-Extraversion-Openness Five Factor Inventory(NEO-FFI)was used at follow up to measure personality traits (60 items) whereitemsare scored on a Likert scale 1-4. These scores measure traits across five personality domains: neuroticism, extraversion, openness to 
experience, agreeableness and conscientiousness (McCrae \& Costa, 2004).Personality traits are relatively enduring (Roberts \& DelVecchio, 2000) and have a high relative trait consistency in all age groups (Srivastava, John, Gosling and Potter, 2003). Therefore, they were unlikely to change significantly during the brief interval between baseline and follow-up, despite adolescents being less stable than adult groups (Pullman, Raudsepp \& Allik, 2006). For that reason, personality traits have been included with other baseline variables for analyses.

The Youth Risk Behaviour Survey (YRBS) was used at follow up to assess for suicidality. The YRBS assesses a wide range of health issues(Centers for Disease Control and Prevention. 2009) butfor the purposes of this analysis, the 5 suicidality items from the YRBS were included rather than the overall total score. May and Klonsky (2011) have previously demonstrated the discriminative and convergent validity of suicidality items of the YRBS. YRBS items 7-11were dichotomised as 0 and 1; items 7-9 (yes=0, no=1) item 10 ( $0=$ no attempted suicide, $1=$ any suicide attempt) and item 11 (0=no suicide attempt or no harm from attempt, 1=harm from suicide attempt). The scores for each of the five items was summed to give a total score (0-5).

\section{Data analyses}

Analyses were performed using Statistical Package for the Social Sciences (SPSS) version 22 for Windows.As true subclinical PLE prevalence is approximately $8 \%$ but higher in adolescents (Van Os et al., 2008; Nelson et al. 2012), participants who had total CAPE scores at or above the 90th percentile at both baseline and follow up (CAPE score= 41- baseline, 36- follow up) were classified as having high levels of PLEs. Total scores at baseline and follow-up weredichotomised on whether they met the threshold for high PLEs.

Persistence was defined ashigh PLEs at both baseline and follow-up. The participants were dichotomised on whether they met these criteria for persistence. Participants were classified 
aseither persistent PLEs ( $\geq 90$ th centile CAPE score at both time points) or non-persistent PLEs ( $\leq 90^{\text {th }}$ centile CAPE score at one or both time points).

To identify risk factors for PLEs and associations, potential variables were first assessed for normality using Q-Q plots. Non-parametric distributions were logged. Laverne's test assessed the equality of variances. Then independent t-tests assessedmean differencesbetween persistent and non-persistent PLEs. Significant variables were included in binary logistic regression, both univariate and multivariate, to assess for effects and associations with early persistent PLES. These regressions produced unadjusted and adjusted odds ratios.

\section{RESULTS}

\section{Sample}

The patient flow of the total possible sample of 4797 are found in Figure 1. Only 590 had sufficient CAPE data at both timepoints, which were used for further statistical analyses. Attrition was not associated with any significant differences in suicidality, gender, age, depression, psychological distress or functioning, Attrition was associatedwith lower CAPE scores $(p=.020)$ but the mean difference was only 1.41 on the scale which is clinically negligible.The mean follow-up time was 410 days (range: 90-726) and there was a significant difference in follow-up times $(t(33)=2.34, p=.025)$; those with persistent PLEs were more likely to have shorter followup times than those with non-persistent PLEs (MD=62 days). In order to account for this effect, follow-up time was included in logistic regression.

\section{INSERT FIGURE 1}

Twenty of 28 Government schools that were approached agreed to participate, compared to five out of 17 Catholic schools and nine out of 15 independent schools. Government schools were significantly more likely than Catholic schools to participate $\left(x^{2}(1)=7.563, p=.006\right)$. 
Of those with sufficient CAPE data at both time points $46.6 \%(274)$ were malewhile females made 53.4\% (314). The mean age was 15.6 (SD 2.64) and 16.6 (SD 0.58) at baseline and follow-up respectively, with no significant difference between sexes.

\section{Early Persistence ofPLEs}

Of participants at baseline and follow-up, 99.2\% and 98.6\% experienced at least 1 PLE "at least sometimes" respectively. However, when a more stringent cut off of experiencing a PLE "nearly always" is used only $27.9 \%$ at baselineand $18.8 \%$ at follow-up did so. As shown in Table 1 ninety-seven participants (11.4\%) at baseline and seventy-one (11.6\%) participants at follow up hadhigh levels of PLEs. Overall, only 30 participants (5.1\%) met the $90^{\text {th }}$ centile threshold at both time points and had early persistent PLEs. Thirty-two participants (5.4\%) at baseline and forty participants $(6.8 \%)$ at follow up hadhigh PLEs at one time only. These72 participants were included with 488 participants who did not have high PLEs at either timepoint in the nonpersistent PLEs group.Overall females showed a higher rate of early persistence (6.4\%) compared to males (3.8\%) and made up 66.6\% $(n=20)$ of the persistent PLEs group.

\section{INSERT TABLE 1}

\section{Baseline associations of early persistentPLEs}

T-tests indicated a significant difference between early persistent PLEs compared with nonpersistent PLEs for all baseline variables except Extroversion and Conscientiousness factors on the NEO scale (see Table2). Earlypersistent PLEs were associated with increased depressive symptoms, psychological distress, open mindedness and neuroticism as well as decreased functioning, follow-up time and agreeableness.

Using univariatebinary logistic regression all measurements were significant as shown in table 4.In multivariate analysis, only depressive score remained significant [OR 1.11 (95\% Cl 1.04- 
1.18), $p=.003$ ]. For every 1 unit increase in CES-D score there is a $10.7 \%$ increase in the probability of having persistent PLEs.

\section{Longitudinal associations of early persistent PLEs}

At follow-up, independent T-test analyses indicated all variables were significantly different between the persistent PLEs and non-persistent PLEs groups, as shown by Table3.Early persistent PLEs were associated with increased depressive symptoms, psychological distress and suicidality, decreased functioning, follow-up time and self-esteem.

Univariate analysis from simple logistic regression showed all five variables to be significantly associated with persistent PLEs as shown in table 4. In multivariate analysis, accounting for all variables, only depressive score [OR: $1.09(\mathrm{Cl}: 1.02-1.16) \mathrm{p}=.010]$ remained significant. For every 1 unit increase in CES-D score there is an 8.6\% increase in the likelihood of having persistent PLES.

INSERT TABLES 2, 3 AND 4

\section{DISCUSSION}

\section{Early Persistence of PLEs}

The prevalence of PLEs was high in this adolescent community sample. Although almost all participants had experienced PLEs using a broad criteria of "at least sometimes", applying a more narrow-criteria of "nearly always" reduced the prevalence to $18-28 \%$ which is consistent with other adolescent PLE prevalence studies (Poulton et al., 2000, Kendler, 1996, van Os, Bijl \& Ravelli, 2000). This reinforces the need for a gold standard assessment and definition of PLEs to increase consistency across studies (Lee et. al. 2015). Only $5.1 \%(n=30)$ of participants showed early persistent PLEs. The rate of early persistence over 6-12 months wasmore than double the persistent PLEs Zammit et al. (2013) found over 6 years, from age 12 
to age $18(2.5 \%)$. This may be due to the different methodologies between the studies. For example, Zammit et al. (2013)assessed presence of psychotic experiences via interview whilst we used a self-report measure.Although self-report has been validated alongside interview techniques to measure PLEs, they may still overestimate the presence of PLEs as there is no opportunity to clarify experiences(Nelson et al. 2012). The follow up interviews at aged 18 in the Zammit et al. (2013) study asked about psychotic experiences since aged 12, and therefore may have been influenced by problems with recall over the preceding 6 years. Additionally, both studies suffered from attrition, following up $67.4 \%$ and $59.7 \%$ of participants in this study and Zammit et al respectively. The higher rate of early persistence may also be due to resolution of psychotic experiences in some individuals over a longer follow up time. This reflects the distinct group of those with early persistent PLEs being identified at an earlier point in theirtrajectory from transitory to persistent PLEs.

\section{Risk Factors and associations forEarly Persistent PLEs}

We found that risk factors for the prevalence of PLEs are also associated with their early persistence (Haug et al. 2016, Nishida et al. 2010). Early persistent PLEs were associated with increased depression, psychological distress (both timepoints) and suicidality (at follow-up) and decreased functioning (both timepoints) and self-esteem (at follow-up). These associations were no longer significant after adjusting for depression.

Increased neuroticism and openness and decreased agreeableness were related to early persistent PLEs. These associations were no longer significant after adjusting for depression. This may be due to overlap between Neuroticism traits and depression and that people with high Agreeableness are less likely to experience depression (Hayward, Taylor, Smoski, Steffens, \& Payne, 2012). Personality traits have been linked to the prevalence of PLEs but have to date only been investigated in one other study on PLE persistence (Bourque et. al. 2017). Further research is required to disentangle the relationship between personality traits 
and depression scores to see how each impacts the trajectory of the other and PLEs over a longer period of time.

PLEs are associated with a range of poor outcomes, including increased risk of both psychotic and non-psychotic disorders(Lin et al. 2015) as well as increased internalising and externalising problems (Healy et al. 2019). This indicates that PLEs appear to be a transdiagnostic marker of mental health problems and confer increased risk of psychopathology in general. Persistent PLEs in particular have been associated with increased risk of psychotic disorders while their relationship to non-psychotic disorders has been under investigated (Healy et al. 2019).

Our study has been able to capture individuals earlier in the trajectory of disorder by identifying those with early persistent PLEs. This provides support underlying changes in depressive symptoms is closely related to early persistent PLEs. This raises questions for the underlying pathophysiology of PLEs, which is unknown, but as stated by Yung and Lin (2016) is likely to represent a heterogenous group; some indicating a neurodevelopmental disorder, some being part of a non-psychotic disorder and some being of no clinical significance (see figure 2a). The early persistence of PLEs being related to depression could be transdiagnostic, reflecting common environmental factors interacting withcommon genetic predisposition for both psychotic and depressive disorders (figure 2b) (Domschke, 2013). This highlights the need to clinically focus on addressing PLEs themselves; their persistence, severity, distress and depressive symptoms to reduce the risk for all future mental health problems. However, it is important to note depression also commonly occurs in the prodromal phase of schizophrenia (Yung \& McGorry, 1996) and the predictive ability of depressive symptoms may reflect an increased propensity to develop prodromal "At Risk Mental State" rather than a mood disorder.Further longitudinal study of this early persistent group will help distinguish between these two possible explanations.

\section{INSERT FIGURE 2}


Zammit et al. (2013) has previously advocated for the need for strong and specific predictors for clinical psychoses and these findings have begun to delineate the course of development of early PLES. Whether or not pre-existing depressive symptomsprecipitate the emergence of early persistent PLEs from transient PLEsor whether they both develop due to common underlying causescan only be confirmed by further longitudinal study.Nonetheless, from a clinical point of view it is important to assess and monitor PLEs especially when they are associated with depression in young people. Given that treatment of depression may reduce PLEs(Yung et. al. 2007), and that depression itself is distressing and associated with a range of poor outcomes in young people (Clayborne, Varin \& Colman, 2019), interventions to treat depression are warranted. Consistent with the staging model, interventions should match the level of symptoms and disability and aim to prevent progression to later stages (McGorry, Hickie, Yung, Pantelis \& Jackson, 2006).

\section{Limitations}

Although a subgroup of persistent PLEs over 6-12 months was identified, participants were only assessed on two occasions. This does not account for fluctuations between measurements and may lead to overrepresentation ofindividuals whose experiences remitted during the interval. Given that PLEs in adolescence may be transient, persistence over 6-12 months does not indicate persistence beyond this timeframe. It does however provide an insight into the early course of PLEs and how they may develop into persistent PLEs. The variation in follow-up times between participants is a limitation. Although we were able to account for the significant difference in follow-up times between groups by including follow-up times in logistic regression, ideally follow-up times would have been kept consistent. Including adolescents from a range of school types provides a more representative and diverse sample. However, we were not able to compare the difference in CAPE score by school type and how that might impact the prevalence of PLES. 
A third (30.42\%) of participants overall and a third (36\%) of participants with high PLEs at baselinewere lost to follow up. This could indicate underrepresentation of persistent PLEs as those with the most severe symptoms may not have been able to complete the follow-up assessment day. However, the proportion of highandlow PLEs lost to follow-up is similarand attrition was related to a marginally lower score on the CAPE at baseline, both of which indicate the sample included in the study is likely to be representative of community adolescent samples.

The use of self-report measures means participants may have misinterpreted items leading to misrepresentation of the prevalence and persistence of PLEs. However, research assistants were on hand to clarify questions and to minimise this effect. In addition, the CAPE has been found to be highly correlated with interview assessed PLEs (Konings, Bak, Hanssen, van Os \& Krabbendam, 2006).

Although we have argued that personality traits are unlikely to change between the two time points, the fact that personality traits were used as a baseline predictor while being measured at follow-up is an additional limitation.

\section{CONCLUSION}

The current longitudinal study has identified a sub-group with early persistent PLEs., These were associated with high levels of depression. Accessible services are needed so that such adolescents can seek help in a non-stigmatising environment where their PLEs and depression can be assessed and monitored. Australia, Ireland and Canada have such services known as "headspace centres", "Jigsaw" and "Access open minds" respectively(Malla et al. 2015). In the UK a service for individuals aged 0-25 has recently been established in Birmingham.

Longer periods of follow up and increased measurement intervals are required to confirm the presence of anearly persistent PLE subgroup and to further understand the evolution of developing early persistent PLEs. 


\section{Acknowledgements}

We would like to thank all the students who took part in the study, the teachers who facilitated the study and the research assistants who worked on the study.

\section{Conflict of Interest statement}

The authors have declared that there are no conflicts of interest in relation to this

study.

\section{Data availability}

Data available on request from the authors

\section{References}

Bechtold, J., Hipwell, A., Lewis, D.A., Loeber, R. \& Pardini, D. (2016). Concurrent and Sustained Cumulative Effects of Adolescent Marijuana Use on Subclinical Psychotic Symptoms. American Journal of Psychiatry, 173(8), 781-789. doi: 10.1176/appi.ajp.2016.15070878

Centers for Disease Control and Prevention. (2009), Youth Risk Behavior Survey. Retrieved from: www.cdc.gov/YRBSS

Clayborne, Z.M., Varin, M., \& Colman, I. (2019). Systematic Review and Meta-Analysis: Adolescent Depression and Long-Term Psychosocial Outcomes. Journal Of The American Academy Of Child \& Adolescent Psychiatry, 58(1), 72-79. doi: 10.1016/j.jaac.2018.07.896

D'Arcy, C., \& Siddique, C. (1984). Psychological distress among Canadian adolescents. Psychological Medicine, 14(3), 615-628. doi: 10.1017/s0033291700015221 
Domschke, K. (2013). Clinical and Molecular Genetics of Psychotic Depression. Schizophrenia Bulletin, 39(4), 766-775. doi: 10.1093/schbul/sbt040

Dominguez, M. D. G., Wichers, M., Lieb, R., Wittchen, H., \& van Os, J. (2009). Evidence That Onset of Clinical Psychosis Is an Outcome of Progressively More Persistent Subclinical Psychotic Experiences: An 8-Year Cohort Study. Schizophrenia Bulletin, 37(1), 84-93. doi: $10.1093 /$ schbul/sbp022

Fusar-Poli, P., Borgwardt, S., Bechdolf, A., Addington, J., Riecher-Rössler, A., Schultze-Lutter, F., Keshavan, M., Wood, S., Ruhrmann, S., Seidman, L., Valmaggia, L., Cannon, T., Velthorst, E., De Haan, L., Cornblatt, B., Bonoldi, I., Birchwood, M., McGlashan, T., Carpenter, W., McGorry, P., Klosterkötter, J., McGuire, P. and Yung, A., 2013. The Psychosis High-Risk State. JAMA Psychiatry, 70(1), p.107.

Goldberg, D., Gater, R., Sartorius, N., Ustun, T., Piccinelli, M., Gureje, O., \& Rutter, C. (1997). The validity of two versions of the GHQ in the WHO study of mental illness in general health care. Psychological Medicine, 27(1), 191-197. doi: 10.1017/s0033291796004242

Haug, E., Øie, M., Andreassen, O., Bratlien, U., Romm, K., Møller, P., \& Melle, I. (2016). The Association between Anomalous Self-experiences, Self-esteem and Depressive Symptoms in First Episode Schizophrenia. Frontiers In Human Neuroscience, 10. doi: 10.3389/fnhum.2016.00557

Hayward, R. D., Taylor, W. D., Smoski, M. J., Steffens, D. C., \& Payne, M. (2012). Association of Five-Factor Model Personality Domains and Facets with Presence, Onset, and Treatment Outcomes of Major Depression in Older Adults. American Journal Of Geriatric Psychiatry, 1. doi: 10.1097/jgp.0b013e3182436200

Healy, C., Brannigan, R., Dooley, N., Coughlan, H., Clarke, M., Kelleher, I., \& Cannon, M. (2019). Childhood and adolescent psychotic experiences and risk of mental disorder: a 
systematic review and meta-analysis. Psychological Medicine, 49(10), 1589-1599. doi: $10.1017 / s 0033291719000485$

Kalman, J., Bresnahan, M., Schulze, T. and Susser, E., 2019. Predictors of persisting psychotic like experiences in children and adolescents: A scoping review. Schizophrenia Research, 209, pp.32-39.

Kelleher, I., Connor, D., Clarke, M., Devlin, N., Harley, M., \&Cannon, M. (2012). Prevalence of psychotic symptoms in childhood and adolescence: a systematic review and metaanalysis of population-based studies. Psychological Medicine, 42(9), 1857-1863. doi: $10.1017 / \mathrm{s} 0033291711002960$

Kendler, K. (1996). Lifetime Prevalence, Demographic Risk Factors, and Diagnostic Validity of Nonaffective Psychosis as Assessed in a US Community Sample. Archives Of General Psychiatry, 53(11), 1022. doi: 10.1001/archpsyc.1996.01830110060007

Konings, M., Bak, M., Hanssen, M., van Os, J., \& Krabbendam, L. (2006). Validity and reliability of the CAPE: a self-report instrument for the measurement of psychotic experiences in the general population. Acta Psychiatrica Scandinavica, 114(1), 55-61. doi: 10.1111/j.1600-0447.2005.00741.x

Lee, K., Chan, K., Chang, W., Lee, E., Hui, C., \& Chen, E. (2015). A systematic review on definitions and assessments of psychotic-like experiences. Early Intervention In Psychiatry, 10(1), 3-16. doi: 10.1111/eip.12228

Lin A, Wood SJ, Nelson B, Beavan A, McGorry P, Yung AR. Outcomes of non-transitioned cases in a sample at ultra-high risk for psychosis. American Journal of Psychiatry. 2015;172(3):249-58. 
Maijer, K., Begemann, M. J. H., Palmen, S., Leucht, S. J. M. C., \& Sommer, I. E. C. (2017). Auditory hallucinations across the lifespan: a systematic review and metaanalysis. Psychological Medicine, 48(6), 879-888. doi: 10.1017/s0033291717002367

Mark, W., \& Toulopoulou, T. (2015). Psychometric Properties of "Community Assessment of Psychic Experiences": Review and Meta-analyses. Schizophrenia Bulletin, sbv088. doi: 10.1093/schbul/sbv088

May, A., \& Klonsky, E. (2010). Validity of Suicidality Items From the Youth Risk Behavior Survey in a High School Sample. Assessment, 18(3), 379-381. doi: $10.1177 / 1073191110374285$

Malla, A., Iyer, S., McGorry, P., Cannon, M., Coughlan, H., \& Singh, S...Joober, R. (2015). From early intervention in psychosis to youth mental health reform: a review of the evolution and transformation of mental health services for young people. Social Psychiatry And Psychiatric Epidemiology, 51(3), 319-326. doi: 10.1007/s00127-015$1165-4$

McCrae, R., \& Costa, P. (2004). A contemplated revision of the NEO Five-Factor Inventory. Personality And Individual Differences, 36(3), 587-596. doi: 10.1016/s01918869(03)00118-1

McGorry, P. D., Hickie, I. B., Yung, A. R., Pantelis, C., \& Jackson, H. J (2006). Clinical Staging of Psychiatric Disorders: A Heuristic Framework for Choosing Earlier, Safer and more Effective Interventions. Australian \& New Zealand Journal Of Psychiatry, 40(8), 616-622. doi: 10.1080/j.1440-1614.2006.01860.x

Nelson, B., Fusar-Poli, P., \& R. Yung, A. R. (2012). Can We Detect Psychotic-like Experiences in the General Population?. Current Pharmaceutical Design, 18(4), 376-385. doi: $10.2174 / 138161212799316136$ 
Nishida, A., Sasaki, T., Nishimura, Y., Tanii, H., Hara, N., Inoue, K...Okazaki, I. (2010). Psychotic-like experiences are associated with suicidal feelings and deliberate self-harm behaviors in adolescents aged 12-15 years. Acta Psychiatrica Scandinavica, 121(4), 301-307. doi: 10.1111/j.1600-0447.2009.01439.x

Poulton, R., Caspi, A., Moffitt, T., Cannon, M., Murray, R., \& Harrington, H. (2000). Children's Self-Reported Psychotic Symptoms and Adult Schizophreniform Disorder. Archives Of General Psychiatry, 57(11), 1053. doi: 10.1001/archpsyc.57.11.1053

Pullmann, H., Raudsepp, L., \& Allik, J. (2006). Stability and change in adolescents' personality: a longitudinal study. European Journal Of Personality, 20(6), 447-459. doi: 10.1002/per.611

Radloff, L. (1977). The CES-D Scale. Applied Psychological Measurement, 1(3), 385-401. doi: 10.1177/014662167700100306

Radloff, L. (1991). The use of the Center for Epidemiologic Studies Depression Scale in adolescents and young adults. Journal Of Youth And Adolescence, 20(2), 149-166. doi: 10.1007/bf01537606

Roberts, B. W., \& DelVecchio, W. F. (2000). The rank-order consistency of personality traits from childhood to old age: A quantitative review of longitudinal studies. Psychological Bulletin, 126(1), 3-25. doi: 10.1037/0033-2909.126.1.3

Radovanović, Z., \& Erić, L. (1983). Validity of the General Health Questionnaire in a Yugoslav student population. Psychological Medicine, 13(1), 205-207. doi: $10.1017 / \mathrm{s} 0033291700050224$

Rosenberg M, (1965) Society and the adolescent self-image. Princeton, NJ: Princeton, University Press, 
Scott, J., Martin, G., Bor, W., Sawyer, M., Clark, J., \& McGrath, J. (2009). The prevalence and correlates of hallucinations in Australian adolescents: Results from a national survey. Schizophrenia Research, 107(2-3), 179-185. doi: 10.1016/j.schres.2008.11.002

Seiler, N., Nguyen, T., Yung, A., \& O'Donoghue, B. (2020). Terminology and assessment tools of psychosis: A systematic narrative review. Psychiatry And Clinical Neurosciences, 74(4), 226-246. doi: 10.1111/pcn.12966

Shi, J., Yao, Y., Zhan, C., Mao, Z., Yin, F., \& Zhao, X. (2018). The Relationship Between Big Five Personality Traits and Psychotic Experience in a Large Non-clinical Youth Sample: The Mediating Role of Emotion Regulation. Frontiers In Psychiatry, 9. doi: 10.3389/fpsyt.2018.00648

Simon, G.E., Coleman, K. J., Yarborough, B. J., Operskalski, B., Stewart, C., Hunkeler, E., \& Beck. A. (2017). Incidence and presentation of first-episode psychosis in a populationbased sample." Psychiatric Services, 68(5), 456-461. http://doi.org/10.1176/appi.ps.201600257)

Srivastava, S., John, O. P., Gosling, S. D., \& Potter, J. (2003). Development of personality in early and middle adulthood: Set like plaster or persistent change?. Journal Of Personality And Social Psychology, 84(5), 1041-1053. doi: 10.1037/00223514.84.5.1041

Stefanis, N., Hanssen, M., Smirnis, N., Avramopoulos, D., Evdokimidis, I., Verdoux, H... Van Os, J. (2002). Evidence that three dimensions of psychosis have a distribution in the general population. European Psychiatry, 17, 61. doi: 10.1016/s0924-9338(02)80276-0

van Os, J., Bijl, R., \& Ravelli, A. (2000). Strauss (1969) revisited: A psychosis continuum in the general population?. Schizophrenia Research,41(1), $8 . \quad$ doi: 10.1016/s09209964(00)90323-2 
van Os, J., Hanssen, M., Bijl, R. V., \& Vollebergh, W. (2001). Prevalence of Psychotic Disorder and Community Level of Psychotic Symptoms. Archives Of General Psychiatry, 58(7), 663. doi: 10.1001/archpsyc.58.7.663

van Os, J., Linscott, R. J., Myin-Germeys, I., Delespaul, P., \& Krabbendam, L. (2008). A systematic review and meta-analysis of the psychosis continuum: evidence for a psychosis proneness-persistence-impairment model of psychotic disorder. Psychological Medicine, 39(2), 179-195. doi: 10.1017/s0033291708003814

Wardenaar, K., Wigman, J., Lin, A., Killackey, E., Collip, D.,Wood, S... Yung, A. R. (2013). Development and Validation of a New Measure of Everyday Adolescent Functioning: The Multidimensional Adolescent Functioning Scale. Journal Of Adolescent Health, 52(2), 195-200. doi: 10.1016/j.jadohealth.2012.06.021

Whiteside-Mansell, L., \& Corwyn, R. (2003). Mean And Covariance Structures Analyses: An Examination Of The Rosenberg Self-Esteem Scale Among Adolescents And Adults. Educational And Psychological Measurement, 63(1), 163-173. doi: $10.1177 / 0013164402239323$

Yamasaki, S., Usami, S., Sasaki, R., Koike, S., Ando, S.,Kitagawa, Y... Sasaki, T. (2018). The association between changes in depression/anxiety and trajectories of psychotic-like experiences over a year in adolescence. Schizophrenia Research, 195, 149-153. doi: 10.1016/j.schres.2017.10.019

Yung, A. R., Buckby, J. A., Cosgrave, E. M., Killackey, E. J., Baker, K., Cotton, S. M., \& McGorry, P. D. (2007). Association between psychotic experiences and depression in a clinical sample over 6 months. Schizophrenia Research,91(1-3), 246-253. doi: 10.1016/j.schres.2006.11.026 
Yung, A. R., Buckby, J. A., Cotton, S. M., Cosgrave, E. M., Killackey, E. J., Stanford, C... Mcgorry P. D. (2005). Psychotic-Like Experiences in Nonpsychotic Help-Seekers: Associations With Distress, Depression, and Disability. Schizophrenia Bulletin, 32(2), 352-359. doi: 10.1093/schbul/sbj018

Yung, A. R., \& McGorry, P. D. (1996). The Prodromal Phase of First-episode Psychosis: Past and Current Conceptualizations. Schizophrenia Bulletin, 22(2), 353-370. doi: 10.1093/schbul/22.2.353

Yung, A. R., \& Lin, A. (2016). Psychotic experiences and their significance. World Psychiatry, 15(2), 130-131. doi: 10.1002/wps.20328

Zammit, S., Kounali, D., Cannon, M., David, A. S., Gunnell, D., Heron, J... Lewis, G. (2013). Psychotic Experiences and Psychotic Disorders at Age 18 in Relation to Psychotic Experiences at Age 12 in a Longitudinal Population-Based Cohort Study. American Journal Of Psychiatry, 170(7), 742-750.doi:10.1176/appi.ajp.2013.12060768 


\section{Tables}

TABLE 1: Participants at baseline and follow up separated by Level of Psychotic-like Experiences (PLEs)

\begin{tabular}{|c|c|c|c|c|}
\hline \multirow{5}{*}{ Baseline } & & \multicolumn{3}{|l|}{ Follow-Up } \\
\hline & & Low PLES & High PLEs & Tota \\
\hline & Low PLES & $488(82.7 \%)$ & $40(6.8 \%)$ & 528 \\
\hline & High PLEs & $32(5.4 \%)$ & $30(5.1 \%)$ & 62 \\
\hline & Total & 520 & 70 & 590 \\
\hline
\end{tabular}


TABLE 2: Independent T-tests comparing participants with Persistent Psychotic-like experiences (PLEs) and Non-Persistent PLEs at baseline

\begin{tabular}{|c|c|c|c|c|c|c|c|}
\hline \multirow[t]{2}{*}{ Baseline } & \multicolumn{4}{|l|}{$M(\mathrm{SD})$} & \multirow[t]{2}{*}{ Mean difference $(95 \% \mathrm{Cl})$} & \multirow[t]{2}{*}{$t(\mathrm{df})$} & \multirow[t]{2}{*}{ Significance $(p)$} \\
\hline & $\begin{array}{l}\text { Non- } \\
\text { Persistent }\end{array}$ & $\begin{array}{l}\mathrm{n}^{\mathrm{a}} \\
560\end{array}$ & Persistent & $\begin{array}{l}\mathrm{n}^{\mathrm{b}} \\
30\end{array}$ & & & \\
\hline $\begin{array}{l}\text { Depression } \\
\text { CES-D }\end{array}$ & $13.49(9.72)$ & 560 & $28.33(10.90)$ & 30 & $-14.85[-18.45,-11.25]$ & $8.10(588)$ & $<.001$ \\
\hline $\begin{array}{l}\text { Functioning } \\
\text { MAFS }\end{array}$ & $72.93(9.97)$ & 550 & $64.33(12.34)$ & 27 & $8.59[3.65,12.54]$ & $3.56(28)$ & .001 \\
\hline $\begin{array}{l}\text { Psychological Distress } \\
\text { GHQ }\end{array}$ & 11.08 (5.92) & 549 & $17.41(7.46)$ & 29 & $-6.33[-9.21,-3.46]$ & $4.5(30)$ & $<.001$ \\
\hline $\begin{array}{l}\text { Personality } \\
N E O-F F I\end{array}$ & & 553 & & 29 & & & \\
\hline -Agreeableness & $41.73(5.00)$ & & $37.83(4.74)$ & & $3.90[2.04,5.77]$ & $4.11(580)$ & $<.001$ \\
\hline -Openness & $38.43(5.92)$ & & $41.41(6.14)$ & & $-2.98[-5.20,-0.76]$ & $2.64(580)$ & .009 \\
\hline -Neuroticism & 32.15 (7.93) & & 41.31 (8.39) & & $-9.16[-12.41,-0.60]$ & $6.04(580)$ & $<.001$ \\
\hline -Extroversion & $42.50(5.87)$ & & $40.34(7.10)$ & & $2.16[-0.06,4.38]$ & $1.91(580)$ & .057 \\
\hline -Conscientiousness & $41.39(7.22)$ & & $38.90(7.40)$ & & $-2.98[-5.20,-0.76]$ & $1.81(580)$ & .070 \\
\hline
\end{tabular}

Note: $\mathrm{Cl}=$ confidence interval, na=number with non-persistent PLEs, nb=number with persistent PLEs

Abbreviations: CES-D = Center for Epidemiologic Studies Depression Scale MAFS = Multidimensional Adolescent Functioning Scale, GHQ $=$ General Health Questionnaire, NEO-FFI= Neuroticism-Extraversion-Openness Five-Factor Inventory, PLE= Psychotic-like Experience 
TABLE 3: Independent T-tests comparing differences between Persistent and Non-persistent groups at follow up

\begin{tabular}{|c|c|c|c|c|c|c|c|}
\hline \multirow[t]{2}{*}{ Follow-up Variable } & \multicolumn{4}{|l|}{$\mathrm{M}(\mathrm{SD})$} & Mean difference $(95 \% \mathrm{Cl})$ & $t(\mathrm{df})$ & Significance $(p)$ \\
\hline & Non-Persistent & $n^{a}$ & Persistent & $\mathrm{n}^{\mathrm{b}}$ & & & \\
\hline $\begin{array}{l}\text { Depression } \\
\text { CES-D }\end{array}$ & $11.38(9.02)$ & 545 & $24.40(9.85)$ & 30 & $-13.02[-16.36,-9.69]$ & $-7.67(587)$ & $<.001$ \\
\hline $\begin{array}{l}\text { Functioning } \\
\text { MAFS }\end{array}$ & $4.34(0.12)$ & 531 & $4.20(0.20)$ & 30 & $0.14[0.07,0.22]$ & $3.94(30)$ & $<.001$ \\
\hline $\begin{array}{l}\text { Psychological Distress } \\
\text { GHQ }\end{array}$ & $9.65(5.20)$ & 544 & $15.5(7.50)$ & 30 & $-5.85[-8.68,-3.02]$ & $-4.22(31)$ & $<.001$ \\
\hline Suicidality YRBS & $0.33(0.91)$ & 550 & $1.23(1.43)$ & 30 & $-0.90[-1.44,-0.36]$ & $-3.40(30)$ & .002 \\
\hline Self-esteem RSE ${ }^{\prime \dagger}$ & $3.46(0.18)$ & 548 & $3.24(0.23)$ & 30 & $0.23[0.16,0.29]$ & $5.38(31)$ & $<.001$ \\
\hline $\begin{array}{l}\text { Note: } \mathrm{Cl}=\text { Confidence Inte } \\
\text { Abbreviations: } \mathrm{CES}-\mathrm{D}=\mathrm{C} \epsilon \\
\text { Health Questionnaire, YR } \\
\text { +Logged }\end{array}$ & $\begin{array}{l}\text { val, } n^{a}=\text { number wit } \\
\text { ter for Epidemiolo } \\
S=\text { Youth Risk Beha }\end{array}$ & $\begin{array}{l}\text { rsiste } \\
\text { es Dep } \\
\text { vey, R }\end{array}$ & $\begin{array}{l}\text { PLEs, } n^{b}=\text { numb } \\
\text { ession Scale MA } \\
==\text { Rosenberg Se }\end{array}$ & vith $p$ & $\begin{array}{l}\text { rsistent PLEs } \\
\text { dimensional Adolescent Fun } \\
\text { Inventory, PLE= Psychotic-lil }\end{array}$ & $\begin{array}{l}\text { oning Scale, } \\
\text { Experience }\end{array}$ & $\mathrm{HQ}=$ General \\
\hline
\end{tabular}


TABLE 4: Binary Logistic Regression of predictor variables at baseline and associations at follow up with Persistence of Psychotic-like Experience (PLEs)

Baseline
Follow-Up 


\begin{tabular}{|c|c|c|c|c|}
\hline & $\begin{array}{l}\text { UOR } \\
(95 \% \mathrm{Cl})[p]\end{array}$ & $\begin{array}{l}\text { AOR } \\
(95 \% \mathrm{Cl})[p]\end{array}$ & UOR $(95 \% \mathrm{Cl})[p]$ & AOR $(95 \% \mathrm{Cl})[p]$ \\
\hline Depression CES-D & $1.11(1.08-1.15)[<.001]$ & $1.11(1.03-1.18)[.003]$ & $1.11(1.07-1.14)[<.001]$ & $1.09(1.02-1.16)[.010]$ \\
\hline Functioning MAFS & $0.93(0.90-0.96)[<.001]$ & $1.00(0.95-1.06)[.981]$ & $0.92(0.88-0.95)[<.001]$ & $0.10(0.05-1.82)[.120]$ \\
\hline $\begin{array}{l}\text { Psychological } \\
\text { Distress GHQ }\end{array}$ & $1.14(1.08-1.19)[<.001]$ & $0.97(0.88-1.07)[.503]$ & $1.14(1.09-1.20)[<.001]$ & 0.99 (0.91-1.09) [.973] \\
\hline \multicolumn{5}{|l|}{$\begin{array}{l}\text { Personality } \\
\text { NEO-FFI }\end{array}$} \\
\hline -Agreeableness & $0.87(0.81-0.93)[<.001]$ & $0.94(0.86-1.03)[.171]$ & & \\
\hline -Openness & $1.08(1.02-1.15)$ [.009] & $1.04(0.97-1.12)[.231]$ & & \\
\hline -Neuroticism & $1.15(1.09-1.20)[<.001]$ & $1.03(0.96-1.10)[.384]$ & & \\
\hline Suicidality YRBS & & & $1.71(1.35-2.17)[<.001]$ & $0.92(0.68-1.26)[.615]$ \\
\hline Self-esteem RSE ${ }^{\dagger}$ & & & $0.01(0.002-0.05)[.009]$ & $0.48(0.02-9.61)[.629]$ \\
\hline $\begin{array}{l}\text { Follow-up Time } \\
\text { (Days) }\end{array}$ & $0.997(0.995-1.00)[.036]$ & $\begin{array}{l}0.998(0.994-1.00) \\
{[.137]}\end{array}$ & $0.997(.995-1.00)[.036]$ & $0.998(0.995-1.00)[.214]$ \\
\hline
\end{tabular}

Note: $\mathrm{Cl}=$ Confidence Interval, UOR= Unadjusted Odds ratio AOR: Adjusted odds ratio

Abbreviations: CES-D = Center for Epidemiologic Studies Depression Scale MAFS = Multidimensional Adolescent Functioning Scale, GHQ= General Health Questionnaire, NEO-FFI=Neuroticism-Extraversion-Openness Five-Factor Inventory, YRBS= Youth Risk Behaviour Survey, RSE=Rosenberg Self-Esteem Inventory, PLE= Psychotic-like experience

+ Logged 
Figure Legends

FIGURE 1: Patient Flow Diagram

FIGURE 2: (a) Bi-directional association between depression and Psychotic-Like experiences (PLEs),(b) Common underlying factor associated with depression and Psychotic-Like experiences (PLEs) 
Figure 2a: Bi-directional association between depression and Psychotic-Like experiences (PLEs)

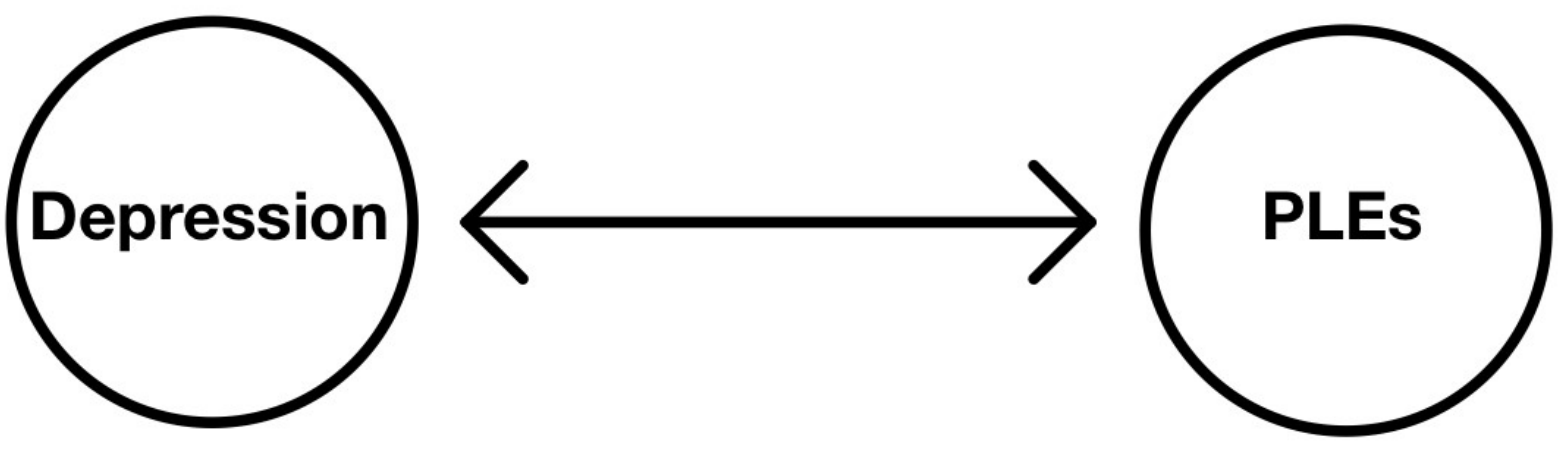

Figure 2b: Common underlying factor associated with depression and PsychoticLike experiences (PLEs)

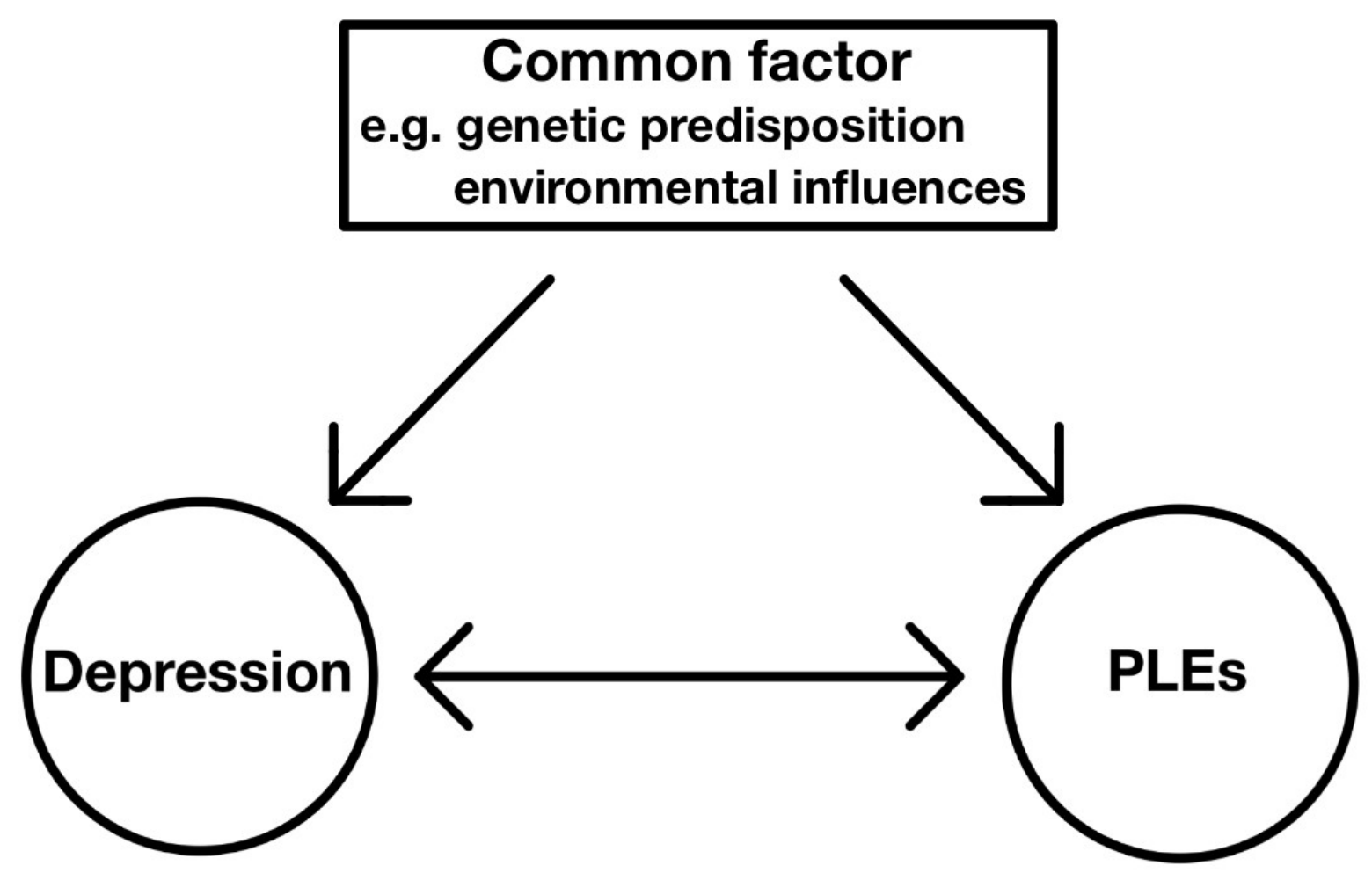


Figure 1: Patient Flow Chart

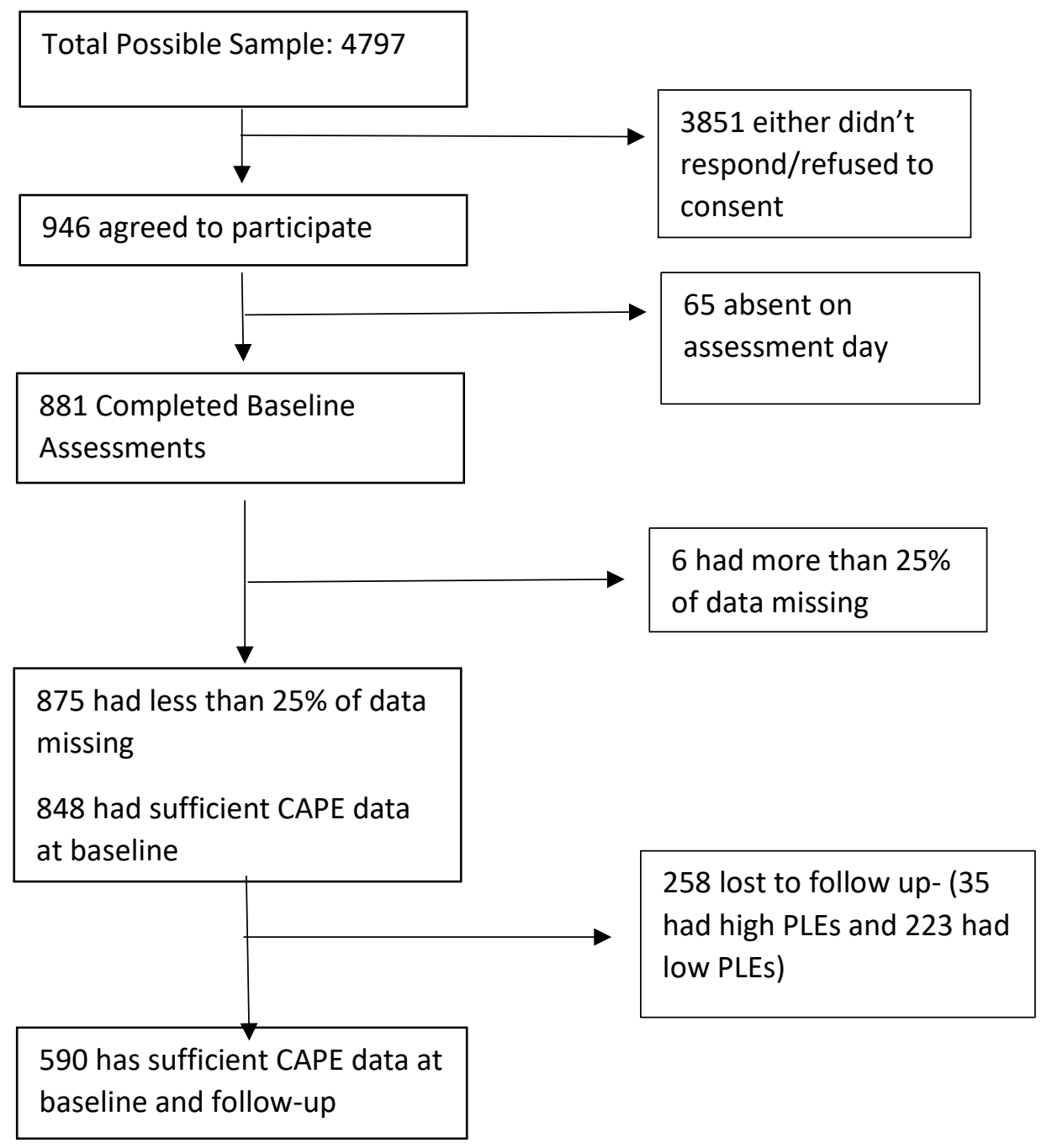




\section{University Library}

\section{- M M I N E R VA A gateway to Melbourne's research publications}

Minerva Access is the Institutional Repository of The University of Melbourne

Author/s:

Hafeez, D;Yung, AR

Title:

Early persistence of psychotic-like experiences in a community sample of adolescents

Date:

2020-11-30

Citation:

Hafeez, D. \& Yung, A. R. (2020). Early persistence of psychotic-like experiences in a community sample of adolescents. EARLY INTERVENTION IN PSYCHIATRY, 15 (6), pp.1575-1583. https://doi.org/10.1111/eip.13096.

Persistent Link:

http://hdl.handle.net/11343/276801 